\title{
TITLE:
}

\section{Palladium-Catalyzed Amination of Aryl Sulfoxides}

$\operatorname{AUTHOR}(\mathrm{S})$ :

Yoshida, Yuto; Otsuka, Shinya; Nogi, Keisuke;

Yorimitsu, Hideki

\section{CITATION:}

Yoshida, Yuto ...[et al]. Palladium-Catalyzed Amination of Aryl

Sulfoxides. Organic Letters 2018, 20(4): 1134-1137

\section{ISSUE DATE:}

2018-02-16

URL:

http://hdl.handle.net/2433/229509

\section{RIGHT:}

This document is the Accepted Manuscript version of a Published Work that appeared in final form in 'Organic Letters', copyright (c) American Chemical Society after peer review and technical editing by the publisher. To access the final edited and published work see https://doi.org/10.1021/acs.orglett.8b00060.; The full-text file will be made open to the public on 2 February 2019 in accordance with publisher's 'Terms and Conditions for Self-Archiving'; この論文は出版社 版でありません。引用の際には出版社版をご確認ご利用ください。; This is not the published version. Please cite only the published version. 


\title{
Palladium-Catalyzed Amination of Aryl Sulfoxides
}

\author{
Yuto Yoshida, Shinya Otsuka, Keisuke Nogi, and Hideki Yorimitsu* \\ Department of Chemistry, Graduate School of Science, Kyoto University, Sakyo-ku, Kyoto 606-8502, Japan
}

Supporting Information Placeholder

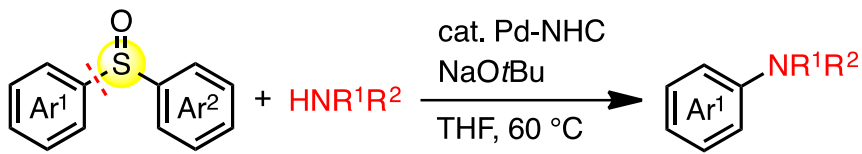

\begin{abstract}
Amination of diaryl sulfoxides with anilines and alkylamines has been accomplished under palladium/ $N$-heterocyclic carbene (NHC) catalysis. Owing to its electron-deficiency, the leaving arenesulfenate anion would be smoothly released from the palladium center to result in uneventful catalyst turnover under milder reaction conditions in comparison with previous $\mathrm{C}-\mathrm{S}$ bond amination reactions. This amination accommodated a wider range of functional groups such as silyl, boryl, methylsulfanyl, and halogen moieties. Regioselective amination of unsymmetrical diaryl sulfoxides was also executed by means of steric bias.
\end{abstract}

Transition metal-catalyzed amination of electrophilic aryl halides or triflates with amines, called Buchwald-Hartwig amination, has attained the central position for the preparation of aromatic amines. ${ }^{1}$ Although aryl iodides or bromides have been widely utilized as the substrates, the amination of less reactive aryl chlorides, ${ }^{2}$ tosylates ${ }^{3}$ and mesylates ${ }^{4}$ has been well established. ${ }^{\text {Ic-h }}$ Furthermore, significant efforts have been devoted to execute amination of more inert $\mathrm{C}-\mathrm{O}^{5-9}$ and $\mathrm{C}-\mathrm{C}^{10,11}$ bonds.

Recently, we became interested in the catalytic transformations of $\mathrm{C}-\mathrm{S}$ bonds of aryl sulfides. ${ }^{12,13}$ Due to their abundance and versatility, organosulfur compounds are expected to be prospective surrogates for aryl halides in transition metal-catalyzed coupling reactions. ${ }^{12,14}$ As a part of our research, we achieved palladium-catalyzed amination of aryl sulfides with anilines and alkylamines. ${ }^{15}$ However, because strongly basic $\mathrm{KN}\left(\mathrm{SiMe}_{3}\right)_{2}$ is essential as a base, the amination suffered from poor functional group tolerance.

During the catalytic cycle of the amination, a thiolate anion derived from an aryl sulfide would tightly coordinate to the palladium center. We assume that $\mathrm{KN}\left(\mathrm{SiMe}_{3}\right)_{2}$ is indispensable to generate highly reactive potassium amide from amine for smooth transmetalation with arylpalladium thiolate. We thus envisioned that a more electron-deficient and less catalystpoisonous leaving sulfur anion would readily depart from the palladium center resulting in smooth catalyst turnover with milder bases. Based on these considerations, we have focused on amination of aryl sulfoxides. However, the transformation seemed to be challenging because a leaving sulfenate anion is valence-isoelectronic with a peroxide anion that potentially oxidizes metal catalysts as well as amines. Nevertheless, inspired by our recent achievement about catalytic transformation of aryl sulfoxides, ${ }^{16}$ we tackled the development of amination of aryl sulfoxides.

Herein we report that amination of diaryl sulfoxides with anilines or alkylamines proceeds by means of a palladium $/ \mathrm{N}$ heterocyclic carbene (NHC) catalyst and $\mathrm{NaO} t \mathrm{Bu}$ as a base. Because of the milder reaction conditions in comparison with our previous amination, the present amination accommodated a wider variety of functional groups such as silyl, boryl, methylsulfanyl and even halogen moieties.

Table 1. Condition screening

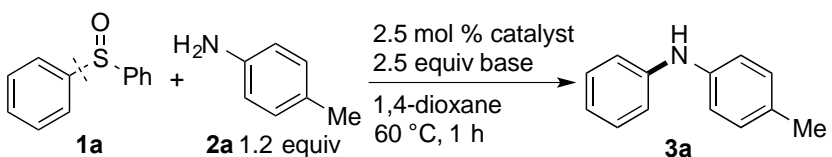

$\begin{array}{llll}\text { entry } & \text { catalyst } & \text { base } & \text { NMR yield (\%) } \\ 1 & \text { SingaCycle-A1 } & \mathrm{KN}\left(\mathrm{SiMe}_{3}\right)_{2} & 7 \\ 2 & \text { SingaCycle-A1 } & \mathrm{KOH} & 17 \\ 3 & \text { SingaCycle-A1 } & \mathrm{K}_{2} \mathrm{CO}_{3} & 0 \\ 4 & \text { SingaCycle-A1 } & \mathrm{K}_{3} \mathrm{PO}_{4} & 0 \\ 5 & \text { SingaCycle-A1 } & \mathrm{KO} t \mathrm{Bu} & 91 \\ 6 & \text { SingaCycle-A1 } & \mathrm{NaO} t \mathrm{Bu} & >99 \\ 7 & \text { SingaCycle-A1 } & \mathrm{LiO} t \mathrm{Bu} & 8 \\ 8^{a} & \text { SingaCycle-A1 } & \mathrm{NaO} t \mathrm{Bu} & >99(97)^{b}(87)^{b, c} \\ 9 & \text { Pd-PEPPSI-IPr } & \mathrm{KO} t \mathrm{Bu} & 11 \\ 10 & \text { Pd(PPh } 3)_{4} & \mathrm{KO} t \mathrm{Bu} & 0 \\ 11 & \text { XPhos Pd G2 } & \mathrm{KO} t \mathrm{Bu} & 47 \\ 12 & \text { none } & \mathrm{KO} t \mathrm{Bu} & 0\end{array}$

${ }^{a}$ THF instead of 1,4-dioxane. ${ }^{b}$ Isolated yield. ${ }^{c} 10 \mathrm{mmol}$ of $\mathbf{1 a}$.

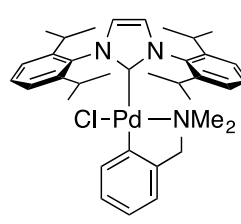

SingaCycle-A1

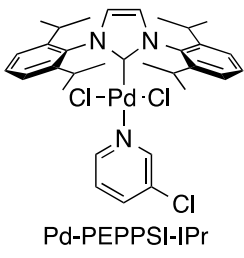

Pd-PEPPSI-IPr

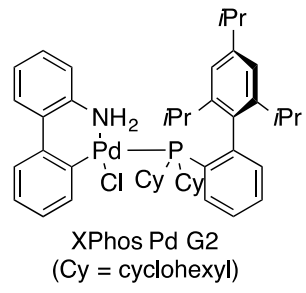

$($ Cy $=$ cyclohexyl)
Our investigation began with the amination of diphenyl sulfoxide (1a) with $p$-toluidine (2a) under the optimal 
conditions for our amination of aryl sulfides ${ }^{15 b}$ with a SingaCycle-A $1^{17}$ precatalyst and $\mathrm{KN}\left(\mathrm{SiMe}_{3}\right)_{2}$ as a base. However, desired aminated product 3aa was obtained only in $7 \%$ yield accompanied by a $93 \%$ recovery of 1 a (Table 1 , entry $1)$. We then screened a series of potassium bases. $\mathrm{KOH}$ as well as milder bases such as $\mathrm{K}_{2} \mathrm{CO}_{3}$ and $\mathrm{K}_{3} \mathrm{PO}_{4}$ were ineffective for the amination (entries 2-4). Fortunately, the yield of 3aa was greatly increased to $91 \%$ by means of $\mathrm{KO} t \mathrm{Bu}$ (entry 5 ). When $\mathrm{NaO} t \mathrm{Bu}$ was used instead of $\mathrm{KO} t \mathrm{Bu}$, 3aa was obtained quantitatively (entry 6). Since the aminated product is more acidic than $\mathbf{2 a}$ and should consume the base additionally, employment of 2.5 equivalents of bases was required for smooth amination. The choice of counter cation of the base is crucial and the yield of 3aa was dramatically diminished with $\mathrm{LiO} t \mathrm{Bu}$ (entry 7). Eventually, after solvent screening, 3aa was isolated in $97 \%$ yield in THF (entry 8). This amination was applicable to a gram-scale reaction; an $87 \%$ yield of $\mathbf{3 a}$ was obtained from $10 \mathrm{mmol}$ of 1a. Difficulty in removing some impurity by silica gel column chromatography led to the slight decrease in the yield of $\mathbf{3 a}$. We also tested other palladium precatalysts in the presence of $\mathrm{KO} t \mathrm{Bu}$. The reaction with $\mathrm{Pd}-$ PEPPSI-IPr ${ }^{18}$ in place of SingaCycle-A1 gave a poor result although they have the same NHC ligand (entry 9). $\mathrm{Pd}\left(\mathrm{PPh}_{3}\right)_{4}$ was completely ineffective and no product was obtained (entry 10). A moderate yield of 3aa was obtained when an XPhosligated palladium complex was used as a catalyst (entry 11). Naturally, no product was obtained without a palladium catalyst, thus the possibility of $S_{N} A r-t y p e$ substitution being denied (entry 12).

\section{Scheme 1. Scope of anilines and alkylamines}
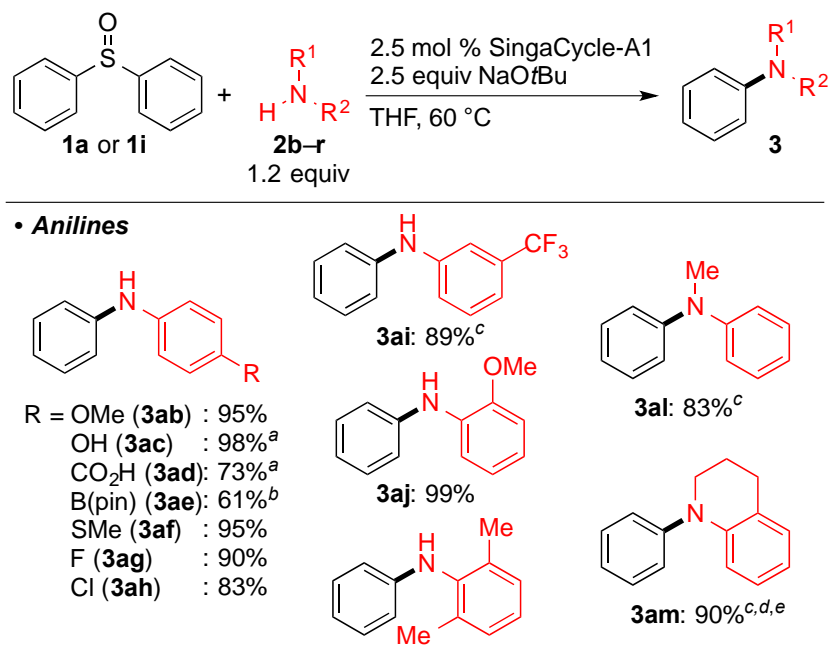

3ak: $95 \%$
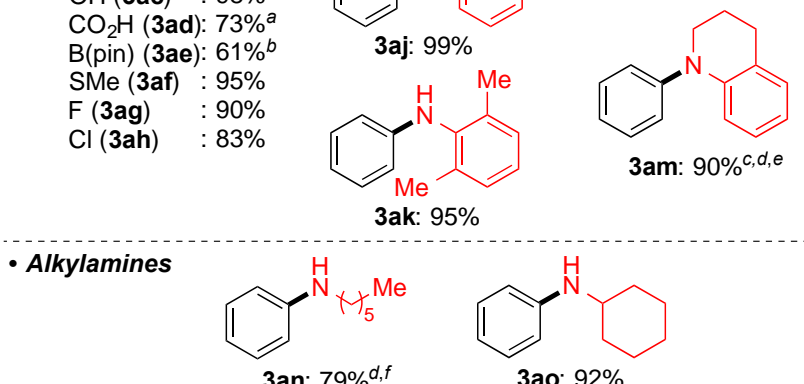

3am: $90 \%$, d,e

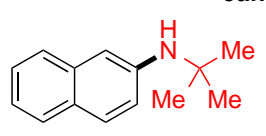

3ip: $92 \%{ }^{c, d}$

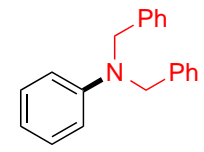

3aq: $85 \% c, d, e$

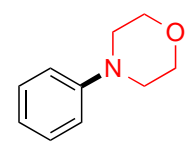

3ar: $86 \%$
${ }^{a} 4$ equiv of $\mathrm{NaO} t \mathrm{Bu} .{ }^{b} 95 \% \mathrm{NMR}$ yield. ${ }^{c} \mathrm{At} 80{ }^{\circ} \mathrm{C} .{ }^{d} \mathrm{KO} t \mathrm{Bu}$ instead of $\mathrm{NaO} t \mathrm{Bu} .{ }^{e} 2.4$ equiv of $2 .{ }^{f} 3$ equiv of 2 . At $40^{\circ} \mathrm{C}$.
With the optimized conditions (Table 1, entry 12) in hand, we then investigated the scope of anilines (Scheme 1). $p$-Anisidine smoothly underwent the amination to afford 3ab in $95 \%$ yield. By means of four equivalents of $\mathrm{KO} t \mathrm{Bu}$, the amination with anilines bearing an unprotected hydroxy or carboxy moiety afforded the target diarylamines 3ac and 3ad. Although the reaction conditions are significantly basic, the pinacolatoboryl moiety on 3ae stayed intact during the amination. Notably, the reaction did not deteriorate a methylsulfanyl or chloro moiety that is potentially reactive under palladium-NHC catalysis. Electron-deficient 3-trifluoromethylaniline (2i) uneventfully underwent the amination. Other electron-deficient anilines having cyano or sulfonyl moiety at their ortho- or parapositions were not involved in the amination resulting in recovery of substrates (not shown). Methoxycarbonyl functionality was degraded via amidation with anilines (not shown). Steric congestion around the amino group did not hamper the amination and the desired products 3aj and 3ak were successfully obtained from $o$-anisidine $(\mathbf{2 j})$ and $2,6-$ xylidine (2k), respectively. The reactions with $N$-alkylanilines $\mathbf{2} \mathbf{l}$ and $\mathbf{2 m}$ gave tertiary amines 3al and 3am, respectively, in high yields.

Besides anilines, alkylamines could be also subjected to this reaction. The reaction of 1a with hexylamine (2n) was carried out with 2.4 equiv of $\mathbf{2 n}$ at $40{ }^{\circ} \mathrm{C}$ in order to suppress diphenylation, and afforded $N$-hexylaniline (3an) in $79 \%$ yield along with diphenylated byproduct in 13\% NMR yield. Cyclohexylamine (2o) and tert-butylamine (2p) successfully participated in the amination without formation of the corresponding diarylated byproducts probably due to the bulkiness of their alkyl moieties. The amination with secondary alkylamines easily proceeded to yield the corresponding tertiary amines 3aq and 3ar.

We then conducted the amination of a series of diaryl sulfoxides 1b-j (Scheme 2). Diaryl sulfoxides bearing an electron-donating or withdrawing group reacted smoothly to provide the corresponding diarylamines in high yields. The trimethylsilyl moiety on 3da remained intact under the reaction conditions. Again, a methylsulfanyl or chloro moiety on 1e or 1f was compatible with the amination. The electron-deficiency of the sulfoxide unit would promote the selective cleavage of the $\mathrm{C}-\mathrm{S}(=\mathrm{O})$ bond over that of the $\mathrm{C}-\mathrm{S}$ or $\mathrm{C}-\mathrm{Cl}$ bond. As a $\pi$ extended diaryl sulfoxide, dinaphthyl sulfoxide $\mathbf{1 i}$ also underwent the reaction to furnish $\mathbf{3 i a}$ in excellent yield. Unfortunately, attempted amination of ortho-substituted diaryl sulfoxide $\mathbf{1 j}$ failed to give the product $\mathbf{3 j a}$ and $89 \%$ of $\mathbf{1 j}$ was recovered.

\section{Scheme 2. Scope of diaryl sulfoxides}

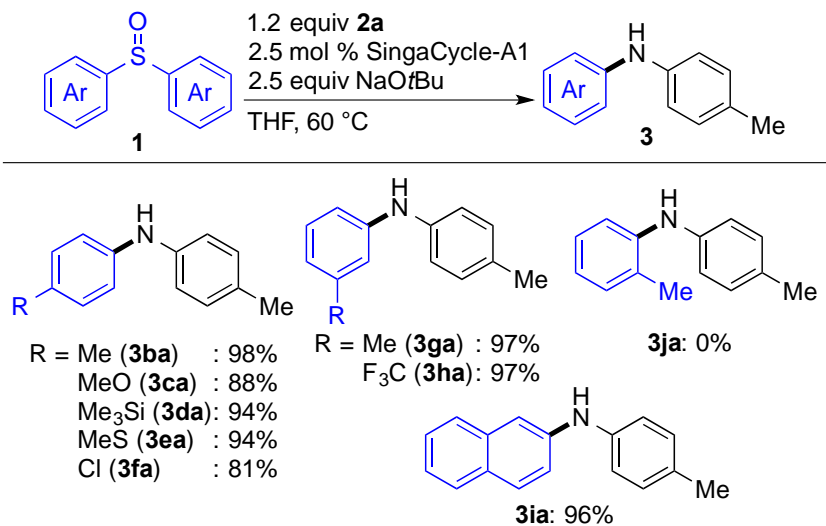


Considering the failure in utilizing ortho-substituted diaryl sulfoxide $\mathbf{1 j}$, we anticipated that regioselective amination of unsymmetrical diaryl sulfoxide would be feasible by means of steric bias (Scheme 3). Indeed, the amination of sterically biased 2,6-dimethylphenyl 4-methoxyphenyl sulfoxide (1k) with 2 a proceeded at the less hindered $\mathrm{C}-\mathrm{S}(=\mathrm{O})$ bond exclusively to afford $\mathbf{3 c a}$ in $80 \%$ yield. In analogous fashions, amide-substituted 11, and heteroaryl sulfoxides $\mathbf{1 m}$ and $\mathbf{1 n}$ furnished the desired diarylamines 3la-na.

Scheme 3. Regioselective amination of unsymmetric diaryl sulfoxides

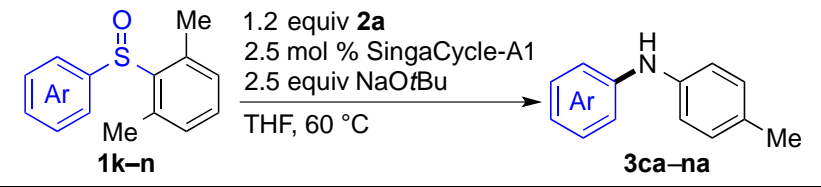<smiles>COc1ccc(Nc2ccc(C)cc2)cc1</smiles>

3ca: $80 \%{ }^{a, b}($ from $\mathbf{1 k})$<smiles>Cc1ccc(Nc2ccccn2)cc1</smiles>

3ma: $53 \%^{c}$

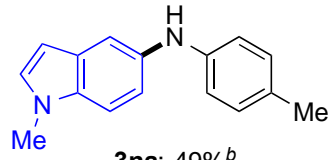

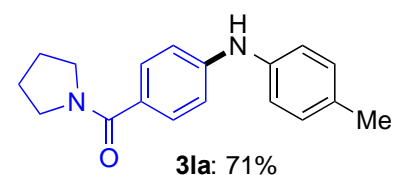

3na: $49 \%{ }^{b}$

${ }^{a} \mathrm{KO} t \mathrm{Bu}$ instead of $\mathrm{NaO} t \mathrm{Bu} .{ }^{b} 80{ }^{\circ} \mathrm{C} .{ }^{c} 10 \mathrm{~mol} \%$ of catalyst.

Although we applied this amination to more accessible alkyl aryl sulfoxides such as methyl phenyl sulfoxide (10) and tertbutyl $p$-tolyl sulfoxide (1p), the reactions proceeded sluggishly and the sulfoxides were recovered (Scheme 4). The more electron-donating alkylsulfinyl groups would slow down the oxidative addition and transmetalation steps. In addition, alkanesulfenate anions generated through the amination would be labile and catalyst poisonous to interfere with the catalyst turnover. ${ }^{16 a, c, 19}$

\section{Scheme 4. Amination of alkyl aryl sulfoxides}
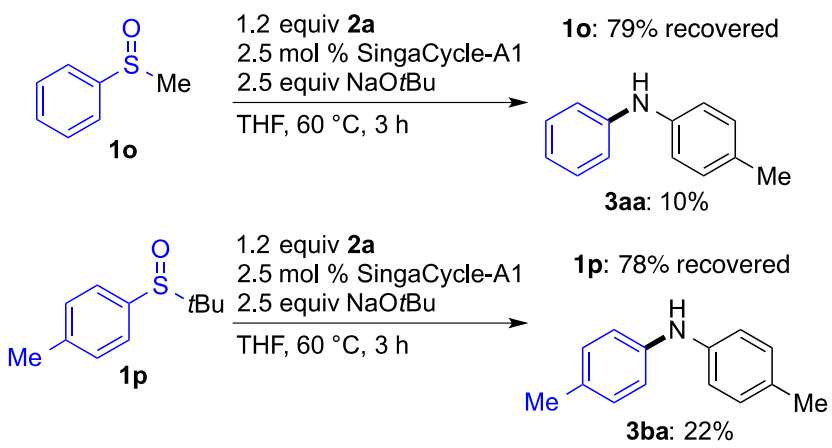

The amination would proceed via a pathway similar to general Buchwald-Hartwig amination: oxidative addition of $\mathbf{1}$ to low-valent palladium, formation of the arylpalladium amide species through substitution of the arenesulfenate anion on the palladium center, and $\mathrm{C}-\mathrm{N}$ bond forming reductive elimination. To confirm the generation of the arenesulfenate anion, we conducted an electrophilic trapping experiment (Scheme 5).
After the amination of $\mathbf{1 a}$ with $\mathbf{2 a}$ under the standard reaction conditions (Table 1, entry 12), the reaction mixture was treated with 2.5 equivalents of iodomethane. As a consequence, desired methyl phenyl sulfoxide 1o was obtained in 93\% yield accompanied with a mixture of 3aa and its methylated product in $98 \%$ total yield. This result clearly indicates that the arenesulfenate anions are surely generated and remain intact in the reaction system without any inhibitions of the amination as opposed to the behavior of alkanesulfenate anions. ${ }^{19}$

Scheme 5. Electrophilic trapping of arenesulfenate anion
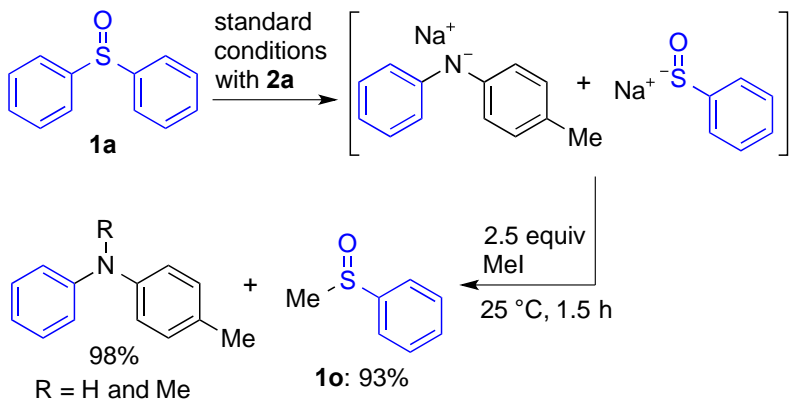

In summary, we have developed palladium-catalyzed amination of aryl sulfoxides with anilines and alkylamines. Owing to its electron-deficiency, the leaving arenesulfenate anion would be readily released from the palladium center, which results in smooth catalyst turnover under milder reaction conditions in comparison with our previous $\mathrm{C}-\mathrm{S}$ bond amination. According to its mild reaction conditions, the present amination was compatible with important yet potentially reactive functional groups such as silyl, boryl, methylsulfanyl, and halogen moieties. Regioselective amination of unsymmetrical diaryl sulfoxides was also accomplished by means of steric bias. Further investigation about metal-catalyzed transformations of aryl sulfoxides is ongoing in our laboratory.

\section{ASSOCIATED CONTENT}

\section{Supporting Information}

The Supporting Information is available free of charge on the ACS Publications website at DOI:xxxxxxxxxxxxxxx

Detailed experimental procedures as well as full spectroscopic data for all new compounds (PDF)

\section{AUTHOR INFORMATION}

\section{Corresponding Author}

*yori@kuchem.kyoto-u.ac.jp

ORCID

Hideki Yorimitsu: 0000-0002-0153-1888

Notes

The authors declare no competing financial interest.

\section{ACKNOWLEDGMENT}

This work was supported by JSPS KAKENHI Grant Numbers JP16H01019, JP16H04109, JP16H06887, as well as JST ACT-C Grant Number JPMJCR12ZE, Japan. S.O. acknowledges a JSPS Predoctoral Fellowship. 


\section{REFERENCES}

(1) Selected reviews: (a) Wolfe, J. P.; Wagaw, S.; Marcoux, J.-F.; Buchwald, S. L. Acc. Chem. Res. 1998, 31, 805. (b) Hartwig, J. F. Angew. Chem., Int. Ed. 1998, 37, 2046. (c) Surry, D. S.; Buchwald, S. L. Angew. Chem., Int. Ed. 2008, 47, 6338. (d) Hartwig, J. F. Acc. Chem. Res. 2008, 41, 1534. (e) Torborg, C.; Beller, M. Adv. Synth. Catal. 2009, 351, 3027. (f) Surry, D. S.; Buchwald, S. L. Chem. Sci. 2011, 2 27. (g) Rutz-Castillo, P.; Buchwald, S. L. Chem. Rev. 2016, 116, 12564. (h) Martín, M.; Rama, R. J.; Nicasio, M. C. Chem. Rec. 2016, 16, 1819.

(2) Pioneering examples of amination of aryl chlorides: (a) Wolfe, J. P.; Buchwald, S. L. J. Am. Chem. Soc. 1997, 119, 6054. (b) Old, D. W.; Wolfe, J. P.; Buchwald, S. L. J. Am. Chem. Soc. 1998, 120, 9722.

(3) The first example of amination of aryl tosylates: Hamann, B. C.; Hartwig, J. F. J. Am. Chem. Soc. 1998, 120, 7369.

(4) Pioneering examples of amination of aryl mesylates: (a) So, C. M.; Zhou, Z.; Lau, C.; Kwong, F. Y. Angew. Chem., Int. Ed. 2008, 47, 6402. (b) Fors, B. P.; Watson, D. A.; Biscoe, M. R.; Buchwald, S. L. J Am. Chem. Soc. 2008, 130, 13552.

(5) Amination of aryl phosphates: Huang, J.-H.; Yang, L.-M. Org. Lett. 2011, 13, 3750.

(6) Amination of aryl sulfamates: (a) Ramgren, S. D.; Silberstein, A. L.; Yang, Y.; Garg, N. K. Angew. Chem., Int. Ed. 2011, 50, 2171. (b) Hie, L.; Ramgren, S. D.; Mesganaw, T.; Garg, N. K. Org. Lett. 2012, $14,4182$.

(7) Amination of aryl carbamates: Mesganaw, T.; Silberstein, A. L.; Ramgren, S. D.; Fine Nathel, N. F.; Hong, X.; Liu, P.; Garg, N. K. Chem. Sci. 2011, 2, 1766.

(8) Amination of aryl esters: (a) Shimasaki, T.; Tobisu, M.; Chatani, N. Angew. Chem., Int. Ed. 2010, 49, 2929. (b) Yue, H.; Guo, L.; Liu, X.; Rueping, M. Org. Lett. 2017, 19, 1788.

(9) Amination of aryl ethers: (a) Tobisu, M.; Shimasaki, T.; Chatani, N. Chem. Lett. 2009, 38, 710. (b) Tobisu, M.; Yasutome, A.; Yamakawa, K.; Shimasaki, T.; Chatani, N. Tetrahedron 2012, 68, 5157. (c) Li, J.; Wang, Z.-X. Org. Lett. 2017, 19, 3723.

(10) Decarbonylative amination of esters: Yue, H.; Guo, L.; Liao, H.-H.; Cai, Y.; Zhu, C.; Rueping, M. Angew. Chem., Int. Ed. 2017, 56, 4282.
(11) Decarbonylative amination of amides: (a) Liu, X.; Yue, H.; Jia, J.; Guo, L.; Rueping, M. Chem. Eur. J. 2017, 23, 11771. (b) Lee, S.-C.; Guo, L.; Yue, H.; Liao, H.-H.; Rueping, M. Synlett 2017, 28, 2594.

(12) Account: Gao, K.; Otsuka, S.; Baralle, A.; Nogi, K.; Yorimitsu, H.; Osuka, A. J. Synth. Org. Chem., Jpn. 2016, 74, 1119.

(13) Recent examples: (a) Gao, K.; Yorimitsu, H.; Osuka, A. Angew. Chem., Int. Ed. 2016, 55, 4573. (b) Baralle, A.; Yorimitsu, H.; Osuka, A. Chem. Eur. J. 2016, 22, 10768. (c) Saito, H.; Nogi, K.; Yorimitsu, H. Chem. Lett. 2017, 46, 1122. (d) Gao, K.; Yamamoto, K.; Nogi, K.; Yorimitsu, H. Synlett 2017, 28, 2956.

(14) Reviews: (a) Sugimura, H.; Okamura, H.; Miura, M.; Yoshida, M.; Takei, H. Nippon Kagaku Kaishi 1985, 416. (b) Naso, F. Pure Appl. Chem. 1988, 60, 79. (c) Luh, T.-Y.; Ni, Z.-J. Synthesis 1990, 89. (d) Luh, T.-Y. Acc. Chem. Res. 1991, 24, 257. (e) Fiandanese, V. Pure Appl. Chem. 1990, 62, 1987. (f) Dubbaka, S. R.; Vogel, P. Angew. Chem., Int. Ed. 2005, 44, 7674. (g) Prokopcová, H.; Kappe, C. O. Angew. Chem., Int. Ed. 2008, 47, 3674. (h) Wang, L.; He, W.; Yu, Z. Chem. Soc. Rev. 2013, 42, 599. (i) Modha, S. G.; Mehta, V. P.; Van der Eycken, E. V. Chem. Soc. Rev. 2013, 42, 5042. (j) Pan, F.; Shi, Z.-J. ACS Catal. 2014, 4, 280.

(15) (a) Sugahara, T.; Murakami, K.; Yorimitsu, H.; Osuka, A. Angew. Chem., Int. Ed. 2014, 53, 9329. (b) Gao, K.; Yorimitsu, H.; Osuka, A. Eur. J. Org. Chem. 2015, 2678.

(16) (a) Yamamoto, K.; Otsuka, S.; Nogi, K.; Yorimitsu, H. ACS Catal. 2017, 7, 7623. (b) Saito, H.; Nogi, K.; Yorimitsu, H. Synthesis 2017, 49, 4769. (c) Yoshida, Y.; Nogi, K.; Yorimitsu, H. Synlett 2017, 28,2561 .

(17) (a) Kantchev, E. A. B.; Ying, J. Y. Organometallics 2009, 28, 289. (b) Peh, G.-R.; Kantchev, E. A. B.; Er, J.-C.; Ying, J. Y. Chem. Eur. J. 2010, 16, 4010.

(18) Reviews: (a) Kantchev, E. A. B.; O’Brien, C. J.; Organ, M. G. Aldrichim. Acta 2006, 39, 117. (b) Organ, M. G.; Chass, G. A.; Fang, D.-C.; Hopkinson, A. C.; Valente, C. Synthesis 2008, 2776. (c) Valente, C.; Çalimsiz, S.; Hoi, K. H.; Mallik, D.; Sayah, M.; Organ, M. G. Angew. Chem., Int. Ed. 2012, 51, 3314.

(19) Alkanesulfenate anions are regarded as being less stable than arenesulfenate anions: (a) Soderman, S. C.; Schwan, A. L. Org. Lett. 2011, 13, 4192. (b) Jia, T.; Zhang, M.; Jiang, H.; Wang, C. Y.; Walsh, P. J. J. Am. Chem. Soc. 2015, 137, 13887. 